\title{
A rare cause of small-bowel bleeding: haemorrhagic small-bowel lymphangioma diagnosed by antegrade double-balloon enteroscopy
}
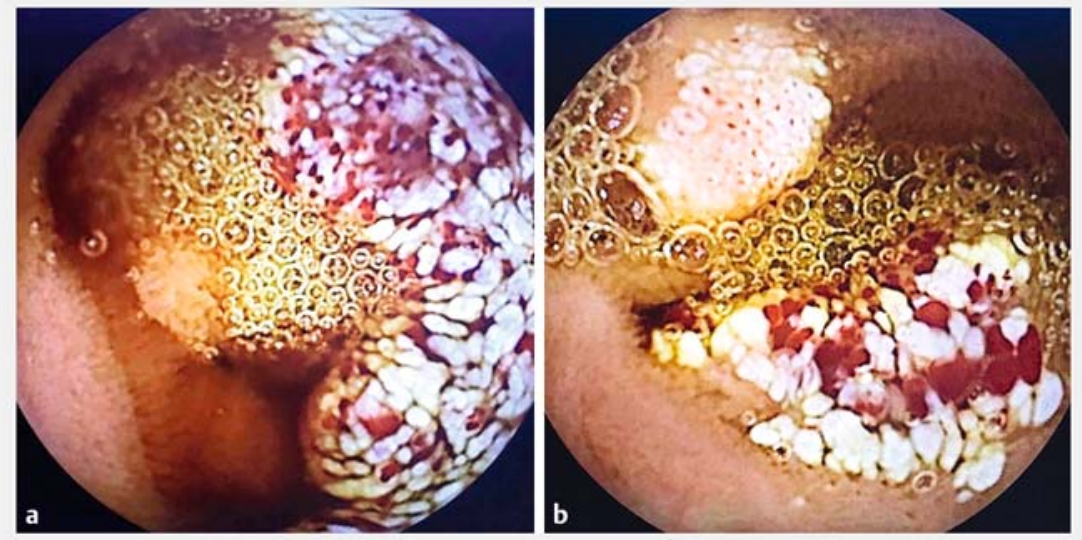

- Fig. 1 Small-bowel capsule endoscopy images showing two white-speckled congested lesions, with active oozing.
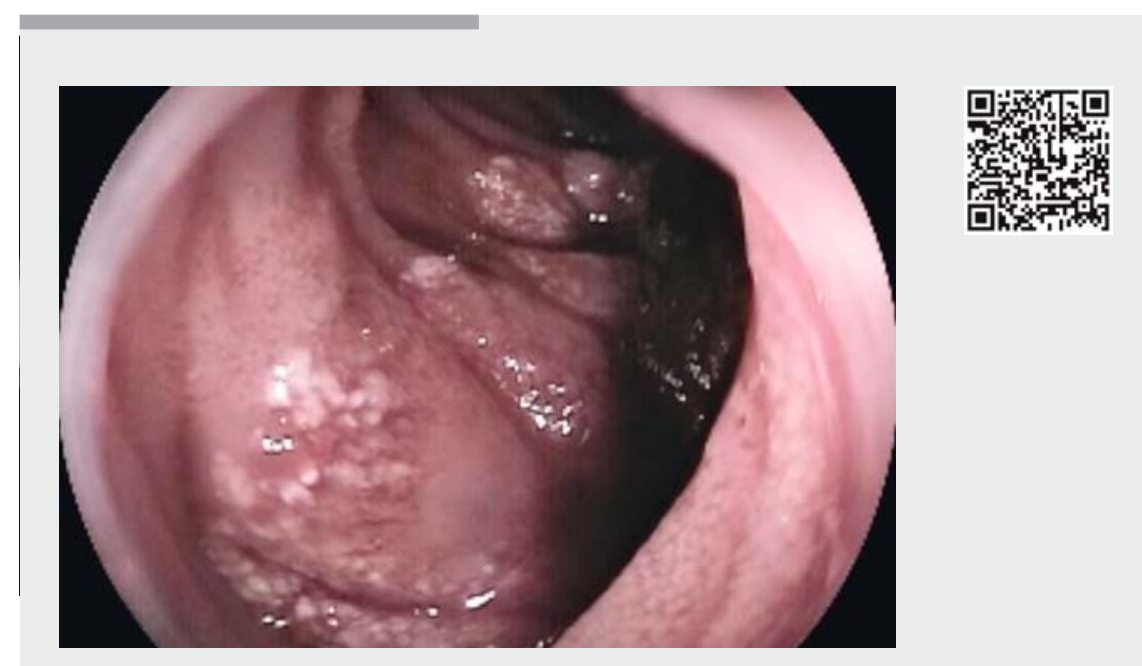

$\checkmark$ Video 1 Small-bowel lymphangioma.

Small-bowel lymphangiomata (SBLs) are benign and relatively uncommon tumors of the lymphatic system [1]. Although SBLs are usually clinically silent, they may rarely present with significant small-bowel bleeding, protein-losing enteropathy, and intussusception [2,3].

A 54-year-old-man with a past medical history of stable chronic lymphocytic leukemia presented with transfusion-depen- dent obscure-overt gastrointestinal (GI) bleeding. Upper and lower GI endoscopies and small-bowel cross-sectional imagining were unremarkable. A smallbowel video capsule endoscopy (VCE) showed a white-speckled congested lesion, with active oozing ( $>$ Fig. 1 ). The lesion was estimated to be about $2 \mathrm{~cm}$ in diameter and was deemed to be located within the jejunum.

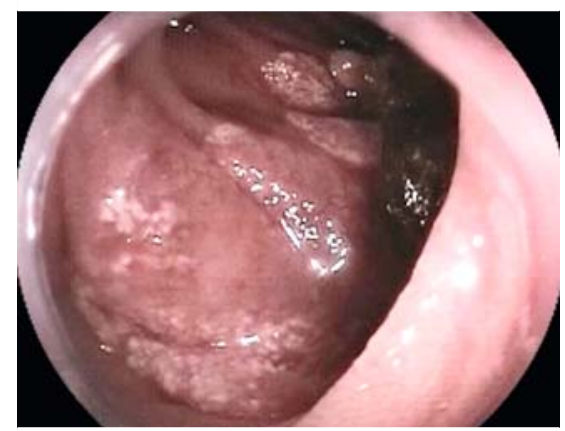

- Fig. 2 Image taken at double-balloon enteroscopy showing a white-yellow appearance of congested villi involved in the lesion.

Antegrade double-balloon enteroscopy (DBE) was subsequently performed. The enteroscope was advanced to an estimated insertion depth of $240 \mathrm{~cm}$ post-pylorus, where the lesion seen at VCE was identified ( $\triangleright$ Fig. 2, \Video 1). This had a white-yellow appearance with overlying severely congested villi giving a "strawberry-like" mucosal pattern. The lesion was not deemed to be endoscopically resectable; multiple biopsies were taken and a reference tattoo was placed proximal to it.

Histopathological exam confirmed a lymphangiomatous etiology without any evidence of dysplasia or malignancy (ฉ Fig.3). Minimally invasive tattooguided laparoscopic resection has been planned.

This case highlights the key, complementary role of small-bowel VCE and DBE for the diagnosis and minimally invasive management of clinically significant SBLs.

Endoscopy_UCTN_Code_CCL_1AC_2AB

Competing interests

Dr. Despott has received research and education grants from Fujifilm, Aquilant Medical, Pentax, and Olympus. 


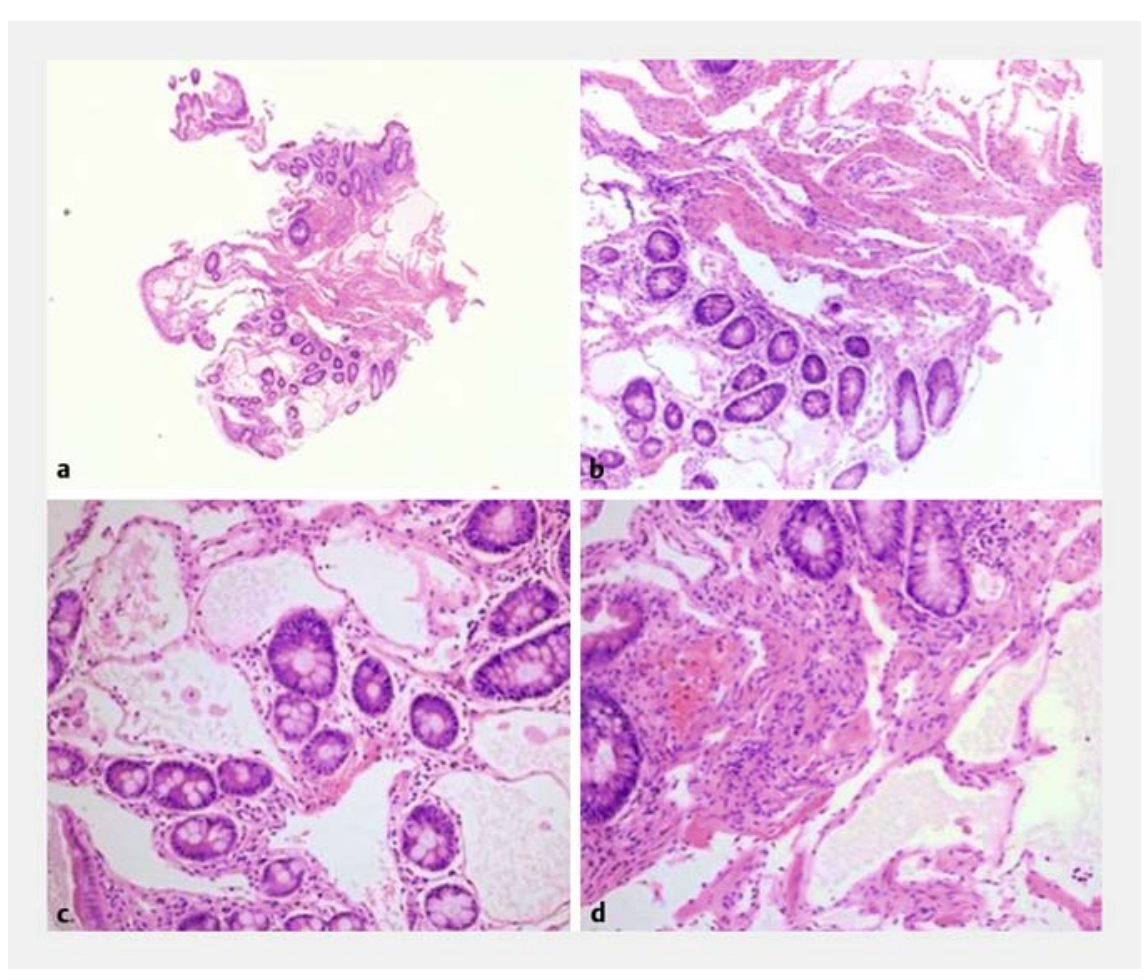

- Fig. 3 Small-bowel mucosal biopsy with hematoxylin and eosin staining captured at low magnification, showing superficial ectatic lymphatic vessel within normal villi and deeper ectatic lymphatic vessels in the submucosa. $\mathbf{a} \times 4$; $\mathbf{b} \times 10$. $\mathbf{c}$, $\mathbf{d}$ Same biopsy captured at higher magnification $(\times 20)$, showing superficial lymphoectasia (monolayer endothelial with no red blood cells) (c) and deeper ectatic lymphatic vessels beyond the muscularis mucosae (d).

The authors

\section{Laura Gaeta ${ }^{1}$, Alberto Murino' ${ }^{1}$ Nikolaos} Koukias' ${ }^{1}$, Bu'Hussein Hayee ${ }^{2}$, Amyn Haji², Andrea Telese' ${ }^{1}$, Edward J. Despott ${ }^{1}$

1 Royal Free Unit for Endoscopy, The Royal Free Hospital and University College London (UCL) Institute for Liver and Digestive Health, London, United Kingdom

2 King's Institute of Therapeutic Endoscopy, King's College Hospital, London, United Kingdom
[1] Akihiko K, Koichiro M, Satoshi H et al. A pedunculated polyp-shaped small-bowe lymphangioma causing gastrointestinal bleeding and treated by double-balloon enteroscopy. World J Gastroenterol 2012; 18: $4798-4800$

[2] Hsu S], Chang YT, Chang MC et al. Bleeding jejunal lymphangioma diagnosed by doubleballoon enteroscopy. Endoscopy 2007; 39: E5-E6

[3] Mehmedovic Z, Mehmedovic M, Custovic MK et al. A rare case of giant mesenteric cystic lymphangioma of the small bowel in an adult: a case presentation and literature review. Acta Gastroenterol Belg 2016; 79: 491-493

\section{Bibliography}

DOI https://doi.org/10.1055/s-0043-123824

Published online: 19.1.2018

Endoscopy 2018; 50: E86-E87

(c) Georg Thieme Verlag KG

Stuttgart · New York

ISSN 0013-726X

\section{ENDOSCOPY E-VIDEOS}

https://eref.thieme.de/e-videos

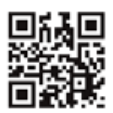

Endoscopy E-Videos is a free access online section, reporting on interesting cases and new techniques in gastroenterological endoscopy. All papers include a high quality video and all contributions are freely accessible online.

(UCL) Institute for Liver and Digestive Health, Pond Street, Hampstead, London NW3 2QG, United Kingdom

Fax: +44-20-74315261

edespott@doctors.org.uk
This section has its own submission website at https://mc.manuscriptcentral.com/e-videos 